\title{
An Analysis of Reputation Restrictions of countries along the Belt and Road's Third Party Credit Reporting Agencies Based on Game Theory - Take China as An Example
}

\author{
Yaxian $\mathrm{Lu}$ \\ International Business School \\ Yunnan University of Finance and Economics \\ Kunming, China \\ 980312863@qq.com \\ Wenbo Du* \\ International Business School \\ Yunnan University of Finance and Economics
}

\author{
Kunming, China \\ 122894558@qq.com
}

Hongmei Li

International Business School

Yunnan University of Finance and Economics

Kunming, China

1198325349@qq.com

\begin{abstract}
This paper analyzes the advantages of third-party credit reporting agencies over traditional credit bureaus and shows that third-party credit reporting agencies provide a convenient financing approach for SMEs among countries along the "The Belt and Road". Taking China as an example, it introduces the development status of China's third-party credit reporting agencies, reveals the obstacles to the operation of third-party credit reporting agencies, and uses game theory to analyze the operational obstructions of reputation restrictions of third-party credit reporting agencies. When extra profits from illegal operations of agencies and cost of supervision by the official regulator are high, agencies have more incentive to take irregularities; when the punishment towards credit rating agency's violations is heavy, reputation loss of the agencies is enough, rewards for official regulators to successfully investigate violations of agencies are rich, the punishment for the official regulators failing to investigate the illegal operation of agencies and punishment for the official regulators failing to investigate the illegal operation of are heavy, credit reporting agencies have less incentive to take irregularities. After above analysis, measures of improving the third-party credit reporting agencies' reputation constraint are put forward.
\end{abstract}

Keywords - Game theory; third-party credit reporting agencies; The Belt and Road; Reputation Restrictions

\section{INTRODUCTION}

Since the "The Belt and Road" initiative has been proposed for five years, many countries along the Belt and Road have reached a number of cooperation in financial cooperation, and the third-party credit reporting agencies, instead of the traditional credit reporting agency led by the credit reporting center of central bank who has mainly served the key state-owned enterprises and large projects, work as an important financial approach for SMEs to obtain funds.
However, in the process of credit investigation, due to the autonomy of third-party credit reporting agencies in terms of their willingness and motivation to restrain their reputation, they have created barriers to reputation and reduced the credit and financing efficiency of SMEs along the Belt and Road. This article takes a Chinese third-party credit reporting agencies as an example to profoundly analyze the barriers to third-party credit bureaucracies' reputation constraint.

\section{The DEVElopMENT OF CHINA's THIRD-PARTY CREDIT REPORTING AGENCIES}

\section{A. The Number and Size of China's Third-party Credit Reporting Market Players}

By the end of 2012, there were about 142 credit reporting agencies in China, of which were 20 governmental credit information service agencies, 50 corporate third-party credit reporting agencies, 70 synthetic third-party credit reporting agencies and 2 personal third-party credit reporting agencies. The 142 third-party credit reporting agencies jointly completed the debt rating of 1670 units and served about 50,000 clients, achieving a total revenue of 2 billion yuan. With the issuance of the corporate third-party credit reporting licenses in 2014 and the opening of the personal third-party credit reporting market in 2015, the number of third-party credit reporting companies in China has rapidly developed. In 2016, the licensed third-party credit reporting agencies in the PRC third-party credit reporting market are approximately 228 , which increased by $60.6 \%$.

*Corresponding author 


\section{B. Market Demand for Third-party Credit Reporting is Increasingly Strong}

The rapid growth of total credit in China has brought the increasing market for third-party credit reporting industry. In December 2016, China's domestic household loans were 33.4 trillion yuan, of which consumer loans were 25.1 trillion yuan and operating loans were 830 million, accounting for $75 \%$ and $25 \%$ respectively. Comparing with the same period of 2015 , it increased by $7.4 \%$ and the amount of increase was 7.3 trillion RMB. The credit market growth has provided market space for third-party credit reporting businesses.

There are many small and medium-sized enterprises in China, bringing the problem that financing is too difficult and expensive to get. SAIC data show that in 2016, due to lack of data, imperfect credit rating, failure of banks and other financial institutions to judge their business risks, China had a total of 80,705,000 market players, but only a few enterprises obtained loans from financial institutions like banks, which will further promote the development and expansion of third-party third-party credit reporting agencies in China.

\section{THE BASIC CONCEPTS AND OPERATIONAL OBSTRUCTIONS OF REPUTATION CONSTRAINTS OF THIRD-PARTY CREDIT REPORTING AGENCY}

\section{A. The Basic Concept of the Reputation Constraints of Third-party Credit Reporting Agencies}

Reputation constraint means that the stakeholder in the market is bound by the non-standard behavior of the third-party credit reporting agencies and is the concrete manifestation of the market constraint in the third-party third-party credit reporting industry. The reputation market must satisfy the two stages of the process which are the screening process and the control process. Stakeholders identify the risk management activities of third-party credit reporting agencies and further implement controls to eliminate the opportunistic behavior of third-party credit reporting agencies. Here the stakeholders are the main body of the market constraint, including the main stakeholders of direct interest-investors and indirect stakeholders - industry associations. Schwarcz [1] argues that because third-party credit reporting agencies are directly linked to reputation, profits are motivated to provide accurate and sufficient credit ratings. However, the outbreak of a series of credit crises has proved that the reputation constraint is not so effective. Frost (2007)[2] argues that the failure to consider reputation constraints lies in the barriers and potential conflicts of interest set by third-party third-party credit reporting agencies.

\section{B. Operational Obstructions of Reputation Constraints of}

Third-party Credit Reporting Agencies

1) Potential conflicts of interest

a) Third-party credit reporting agencies rely on third-party credit reporting fees

Companies or organizations applying for a rating need to pay a rating fee, which generally includes initial fees and annual maintenance fees. The potential for conflict of interest arises because third-party credit reporting agencies may be tempted by high rating fees and make lenient assessments for client companies. In addition, large companies may use their influence to put pressure on third-party credit reporting agencies.

\section{b) Development of subsidiary business}

If a customer purchases ancillary services, the third-party credit reporting agencies may offer a credit rating, even if the information collected does not support this rating. Although the current subsidiary business accounts for a small share of the business of third-party credit reporting agencies, with the diversification of development, such potential conflicts of interest should arouse the attention of regulators.

2) The disclosure of third-party credit reporting information is not clear

a) The transparency of the third-party credit reporting process

To the public, the third-party credit reporting process seems like a "black box" and they do not understand how credit ratings are generated. The lack of transparency of third-party credit reporting agencies creates an island effect on information such as the number of companies each analyst is responsible for analyzing, the frequency of formal reviews, the frequency of official reviews on a quarterly basis, and the number of companies rated quarterly or annually.

b) The rating result information is asymmetric

Although third-party credit reporting agencies claim that both the public and ratings users will be notified of the rating results at the same time, users of the rating results will get more detailed information, and they can even talk with analysts and get the rating results ahead of time, causing the leaked information.

c) The quality of analysts can not be standardized

Normally, analysts rate their clients based on the offered information rating, but seldom review the accuracy and completeness of that. Hard-working standard of credit analysts is difficult to determine, thus affecting the fact that third-party credit reporting quality is difficult to guarantee.

\section{ANALYSIS OF REPUTATION CONSTRAINTS OF THIRD-PARTY CREDIT REPORTING AGENCIES BASED ON GAME THEORY}

Assuming that any player in the game fully understands the benefits of himself and his opponent in various situations during the game, and the decisions made are completely rational, and they make a decision at the same time, that is,for the third-party credit reporting agencies and the official regulator all information is complete. Therefore, a static game model between third-party credit reporting agencies and official supervisors is established.

\section{A. Participants and Hypothesis}

\section{1) Participants}

There are two participants in the official regulatory game: (1) The regulatory body. It is an important guarantee to regulate the behavior of third-party credit reporting agencies in order to eliminate irregular behaviors of third-party credit reporting agencies. (2) third-party credit reporting agencies. The main task of a third-party credit reporting agencies is to follow an independent standpoint and uphold the principles of 
independence, objectivity and fairness, use a standardized rating system and criteria, apply a scientific method of rating, perform a rigorous rating process, in order to reveal the credit risk of rating object. There is strategic dependency between regulators and third-party credit reporting agencies. From the point of third-party credit reporting agencies, its strategy includes two:First they would pay attention to reputation, rate with caution, that is ,third-party credit reporting agencies adopt strict evaluation criteria to lower error ; Secondly, they would not pay attention to reputation, rate with no standard, that is, third-party credit reporting agencies adopt loose evaluation criteria and get the low accuracy and low cost. The probabilities of the two are denoted by $\mathrm{P}$ and 1-P, respectively. From the regulatory perspective, the strategies are respectively to supervise and not supervise third-party credit reporting agencies. $\mathrm{q}$ and 1-q, respectively, represent the probabilities that the official regulate and not regulate toward third-party credit reporting agencies.

\section{2) Hypothesis}

To facilitate the analysis, the following hypothesis are made:

Hypothesis 1: Both parties involved in the game are rational, and they will make the most rational decisions under certain constraints.

Hypothesis 2: The efficiency of the official is high, which means once a third-party credit reporting agencies conducts illegal operations or unfair ratings, it must be detected and imposed a certain amount of fines as long as the official regulates it. The penalty amount is a certain percentage of the revenue of this business, here assumed to be $\mathrm{k}(0<\mathrm{k}<1)$. At the same time the regulator need to be paid as for travel costs, on-site inspection costs and so on, here assumed to be $\mathrm{T}$.

Hypothesis 3: If the official regulator does not perform regulatory functions, and the third-party credit reporting agencies conduct unfair ratings and the graded products have breached the contract, they will be punished by the higher authorities. Here we assume the punishment fee is M. If the official regulator performs the regulatory function and investigates the unfair conduct or irregularities of the third-party credit reporting agencies, the regulator will be rewarded $\mathrm{W}$ for the increasing prestige recognized and affirmed by the public.

Hypothesis 4: In addition to be punished by fines, the investigated third-party credit reporting agencies will also be disclosed to public investors in a certain form by the government regulators, which will increase the reputation loss of third-party credit reporting agencies, thus further affect the third-party credit reporting agencies operations, bring problem that investors no longer believe rating result given by the third-party credit reporting agencies and the issuing company will not buy the third-party credit reporting agencies products. Its market share will continue to decline until it disappears completely in the market. This loss is measured as L.

Hypothesis 5: third-party credit reporting agencies need to pay a certain amount of credit-rating cost positively related to the quality of third-party credit reporting products. If a third-party credit reporting agencies conducts a fair rating, adopts strict evaluation criteria, the cost will be higher. Conversely, if the more loosing evaluation criteria is used, the higher of error rate is, the less time and energy is spent ,then the lower of the cost will be. c represents the cost, of which $\mathrm{C} 1$ corresponds to the cost of compliance operations, C2 corresponds to the cost of non-compliance operations respectively, and $\mathrm{C} 1>\mathrm{C} 2$. $\mathrm{R}$ represents the business income obtained by third-party credit reporting agencies.

\section{B. Static Game Equilibrium Analysis}

THE PAYMENT MATRIX OF OFFICIAL REGULATORS AND CREDIT REPORTING AGENCIES

\begin{tabular}{|l|c|c|}
\hline & Treasure reputation (fair rating) & Do Not Treasure reputation (unfair rating) \\
\hline Regulate (p) & $-\mathrm{T}, \quad \mathrm{R}-\mathrm{C} 1$ & W-T,R-C2-Rk-L \\
\hline Do Not Regulate (1-p) & $0, \mathrm{R}-\mathrm{C} 1$ & $-\mathrm{M}, \mathrm{R}-\mathrm{C} 2$ \\
\hline
\end{tabular}

$\frac{\partial E 2}{\partial p}=-p T+(1-p)(W-T)+(1-p) M=0$

The expected earnings of the third-party credit reporting agencies and the official regulator are represented as E1 and E2 respectively:

$\mathrm{E} 1=\mathrm{pq}(\mathrm{R}-\mathrm{C} 1)+\mathrm{p}(1-\mathrm{q})(\mathrm{R}-\mathrm{c} 1)+(1-\mathrm{p}) \mathrm{q}(\mathrm{R}-\mathrm{C} 2-\mathrm{Rk}-\mathrm{L})+(1-\mathrm{p})(1-\mathrm{q})(\mathrm{R}-\mathrm{c} 2)$

$\mathrm{E} 2=\mathrm{pq}(-\mathrm{T})+\mathrm{p}(1-\mathrm{q}) * 0+(1-\mathrm{p}) \mathrm{q}(\mathrm{W}-\mathrm{T})+(1-\mathrm{p})(1-\mathrm{q})(-\mathrm{M})$

Deriving E1 from p, we get the first derivative condition that third-party credit reportinginstitution pays attention to reputation (fair rating)

$$
\frac{\partial \mathrm{E} 1}{\partial \mathrm{E} p}=\mathrm{C} 2-\mathrm{C} 1+\mathrm{qRk}+\mathrm{qL}=0
$$

Derive E2 from $\mathrm{p}$ and obtain the first derivative condition for the optimization of official supervision: $\partial \mathrm{p}$

(1) (2), we get the optimal probability $q^{*}$ of official regulation and the optimal probability $\mathrm{p}^{*}$ of third-party credit reporting agencies' compliance operation under the equilibrium state:

$$
\begin{aligned}
& \mathrm{q}^{*}=\frac{\mathrm{C} 1-\mathrm{C} 2}{\mathrm{Rk}+\mathrm{L}} \\
& \mathrm{P}^{*}=1-\frac{\mathrm{T}}{\mathrm{W}+\mathrm{M}}
\end{aligned}
$$




\section{Analysis of the Influencing Factors of Equilibrium Results}

1) The Influencing factors of optimum Probability $q^{*}$ for Official Regulators

From (1), we can see that the optimal probability q* of the official regulator is affected by the cost spread $\mathrm{C} 1-\mathrm{C} 2$ of fair rating and unfair rating, penalty factor $\mathrm{k}$ and reputation loss $\mathrm{L}$ caused by unfair rating.

The larger $\mathrm{C} 1-\mathrm{C} 2$, the greater the optimal supervision probability of the official regulator.

Find the first derivative of $\mathrm{q}^{*}$ for $\mathrm{C} 1-\mathrm{C} 2$ :

$$
\mathrm{q}(\mathrm{C} 1-\mathrm{C} 2)^{*}=\frac{1}{\mathrm{Rk}+\mathrm{L}}>0
$$

That is, $\mathrm{q}^{*}$ is a monotonically increasing function of $\mathrm{C} 1-\mathrm{C} 2$. In other words, the larger the gap of costs between compliance and non-compliance, the more likely regulatory oversight will be provided by the official regulator. Therefore, third-party credit reporting agencies tend to prefer non-compliant operations to reduce costs when targeting the same capital markets. If there is not much difference between the two, the third-party credit reporting agencies will consider other factors to conduct the behavior selection. If the gap between the two is larger, meaning that the higher the extra profit from illegal operations, the more motivated the third-party credit reporting agencies is to take the irregularities and the greater the probability of optimal regulation.

The greater the intensity of the official supervisory penalty punishment, the less the optimal supervision probability of the official supervisor. Find the first derivative of $\mathrm{q}^{*}$ for $\mathrm{k}$ : $\mathrm{q}(\mathrm{K}) *=-\frac{C 1-C 2}{R k^{2}}<0$

That is, $\mathrm{q}^{*}$ is a monotonically decreasing function of $\mathrm{k}$. In other words, when the third-party credit reporting agencies' irregularities are found and penalized heavier, the third-party credit reporting agencies' motivation to run illegally will be less, and official's vigor to regulate will be less correspondingly.

The greater the reputation loss of a third-party credit reporting agencies, the smaller the probability of unfair rating.

Find the first derivative of $\mathrm{q}^{*}$ for $\mathrm{L}$ :

$$
\text { q }(\mathrm{L}) *=-\frac{\mathbf{C} \mathbf{1}-\mathbf{C} \mathbf{2}}{\mathbf{R L}^{2}}<0
$$

That is, $\mathrm{q}^{*}$ is a monotonically decreasing function of L. In other words, the greater of reputation loss caused by illegal operation, the less motivated the third-party credit reporting agencies is to unfairly rate, and official's vigor to regulate will be less correspondingly.

2) The influencing Factors of optimum Probability $p^{*}$ for third-party credit reporting agencies

The larger the cost of supervision by the official regulator, the smaller the probability of fair rating by the third-party credit reporting agencies.
Find the first derivative of $\mathrm{p}^{*}$ for $\mathrm{T}$ :

$$
\mathrm{P}(\mathrm{T}) *=-\frac{1}{\mathrm{~W}+\mathrm{M}}<0
$$

Regulators will provide less regulation when regulatory costs are higher. Therefore, the probability of operating in compliance with the requirement and providing a correct and fair rating will be less. Instead of strict rating method, loosing standard will be adopted and credit reports full of errors will be offered to the public.

The bigger the reward to the official for the successful investigation and punishment of a non-operating third-party credit reporting agencies, the greater the probability that a third-party credit reporting agencies will rate fairly.

Find the first derivative of $\mathrm{p}^{*}$ for $\mathrm{W}$ :

$$
\mathrm{P}(\mathrm{W}) * \frac{\mathrm{T}}{(\mathrm{W}+\mathrm{M})^{2}}>0
$$

The official tends to regulate strictly when it comes to the bigger reward for the reason that it successfully investigates and deals with the third-party credit reporting agencies operating illegally, in which case, the higher the probability that a third-party credit reporting agencies is investigated and fined, the greater the probability of its compliance management.

c) The heavier punishment $\mathrm{M}$ for the reason that the official failed to investigate and deal with the non-compliance of the third-party credit reporting agencies, the higher the probability that the third-party credit reporting agencies will be impartially graded.

Find the first derivative of $\mathrm{P}^{*}$ for $\mathrm{M}$ :

$$
\mathrm{P}(\mathrm{W})^{*}=\frac{\mathrm{T}}{(\mathrm{W}+\mathrm{M})^{2}}>0
$$

The regulators tends to censor strictly when regulators are fined more and bring more negative effects as for their neglect of duty, in which case the higher the probability that a third-party credit reporting agencies is investigated and fined, the greater the probability of its compliance operation.

\section{MeAsures of IMPROVING THE THIRD-PARTY CREDIT REPORTING AGENCIES’ REPRTATION CONSTRAINT}

\section{A. To Promote the Reasonableness and Effectiveness of Information Disclosure}

The primary task of cultivating the reputation constraint of the third-party third-party credit reporting industry in China is to complete the information disclosure of the third-party credit rating. Improving the transparency of third-party credit reporting agencies through information disclosure and increasing investors' understanding about the operation of third-party credit reporting agencies can facilitate the implementation of reputation constraints [3]. 


\section{B. Minimize the Fluctuation Range of Rating Quality}

Once the market authority is established, to some extent it will be fixed, which was proved by the financial crisis in Southeast Asia. After the outbreak of the incident, though Moody's and S \& P, were widely challenged and blamed, but it failed to shake their dominance in the third-party credit reporting community. The existence of a range of quality fluctuations means that even a change in the rating quality, such as a temporary deviation in quality, does not harm its reputation or stop issuers and investors from relying on third-party credit reporting decisions [4]. In this way third-party credit reporting agencies can reduce costs and give a rating in lower quality, and more importantly, they can use this to coerce issuers or collude with issuers to discourage competitors or increase profits. Therefore, when strengthening the supervision of credit rating, China should implement corresponding policies to minimize the range of fluctuation of rating quality, such as explicitly stipulating the scope of deviation from the rating grade. When it is out of the scope, regulators can take action to use official prestige to sway their market authority, such as public announcement of criticism, or criticize third-party credit reporting agencies. Moreover, regulators can establish a third-party credit reporting measures ranking mechanism to regularly evaluate and rank the performance of member institutions.

\section{Give full Play to the Role of Third-party Credit Reporting Industry Association}

Under the government's authorization or commission, industry association may assume some of the functions of industry regulation. In response to the poor situation caused by the absence of professional standards in China's third-party credit reporting agencies, there is an urgent need for a unified national third-party credit reporting industry association to improve the management of the third-party credit reporting industry, which is of great significance to promote the healthy, continuous and orderly development of China's third-party credit reporting industry[5].

\section{Weaken Over-reliance on External Rating Results}

After the financial crisis, regulators in various countries have repeatedly reviewed the regulatory dependence on the third-party credit reporting results, taken deregulation policy, weakened the certification role of third-party credit reporting agencies, avoided investors' over-reliance on external ratings, and reduced the its influence on the financial system. In the existing regulatory rules of China, there is also the case of directly quoting the rating results.

With this lesson from the financial crisis, China should supervise the third-party credit reporting agencies' results while retaining the central role of third-party credit reporting and monitoring. In terms of the actual development of the bond market, regulators may gradually remove the regulatory provisions directly reference to the third-party credit reporting results, select and approve the third-party credit reporting results by the market mechanism, guide the third-party credit reporting agencies to truly serve investors, and thus improve the independence, objectivity and fairness of third-party credit reporting agencies through market force, so that the third-party credit reporting industry can truly return to its true role as offering information and monitoring.

First, the short-term behavior of third-party credit reporting agencies will not be conducive to the healthy operation of third-party third-party credit reporting markets, therefore, we must first formulate the ways, standards, scopes and procedures for market withdrawal scientifically. A multi-level, multi-channel exit mechanism should be established, which should be suitable for both the national and regional market, the entire and partial business, long term and short term exit in order to realize the survival of the fittest in the market and ensure the reliability of the third-party credit reporting results. Second, we need to set the relevant laws and regulations to ensure the third-party third-party credit reporting market exit standardized and orderly manner. In the end, the regulators should follow the principle of market as for the exit method, avoiding to be intervened by non-market administrative means.

\section{ACKNOWLEDGMENT}

This paper is sponsored by the Foundation for Talent Introduction Project of Yunnan University of Finance and Economics (Grant No.80059900194).

\section{REFERENCES}

[1] Schwarcz, Steven L., "Prviate Ordering of Public Markets: The rating Agency Paradox", University of Illiois Law Review,2002 vol.1.

[2] Frost, Carol Ann, "Credit Rating Agencies in Capital Markets: A Review of Research Evidence on Selected Criticisms of the Agencies", Journal of Accounting, Auditing and Finance, 2007,vol.22 .

[3] Bar-Isaac, Heski, "Imperfect Competition and Reputational Commitment", Economics Letters, 2005,vol.89 .

[4] Mathis, Mc Andrews, Rochet, "Rating the Raters: Are Reputation Concerns Powerful Enough to Discipline Rating Agencies?” Journal of Monetary Economics, 2009,vol.56.

[5] Millon, Thakor, "Moral Hazard and Information Sharing: A Model of Financial Information Gathering Agencies", Journal of Finance, 1985, vol.40 . 